\title{
Assessment of Intention to Use Contraceptive Methods With Spatial Distributions and Associated Factors Among Women in Ethiopia: Evidence From EDHS 2016
}

Girma Gilano ( $\nabla$ gilanog@yahoo.com )

Arba Minch University https://orcid.org/0000-0002-5847-1425

Samuel Hailegebreal

Arba Minch University

\section{Research}

Keywords: Intention, women, spatial, contraceptive, Ethiopia

Posted Date: April 5th, 2021

DOI: https://doi.org/10.21203/rs.3.rs-325262/v1

License: (a) (1) This work is licensed under a Creative Commons Attribution 4.0 International License. Read Full License 


\section{Abstract}

Background: Modern contraceptive methods have immense influences on the health of mothers and their children. Using contraceptive methods is seen to control family size and unnecessary pregnancies. And it leads to peaceful and known family status. Considering different factors like resources and various cultural aspects, assessing the intention to use might bring areas with these problems into the light to act on them.

Methods: We used multilevel logistic regression and spatial analysis techniques to the data from the 2016 Ethiopian demographic health survey. We downloaded the data from the EDHS website after the approval of the request for the data. We pooled the data to assess the intention to use contraceptive methods among 15-49 age women. After applying bivariate and multilevel binary logistic regression, we presented the information on Community and Individual level using tables, figures, and spatial distribution. We applied a p-value $<0.05$ and adjusted odds ratios (AOR) with $95 \%$ confidence intervals (Cl).

Result: the intention to use contraceptive methods was $44.11 \%$. Spatially, we found intention to use contraception highly clustered in North and Western Ethiopia. The average number of children (4.5 \pm 2.9$)$, age at first cohabitation (16.9 \pm 3.99$)$, and the ideal number of children (4.77 \pm 2.0$)$. Some other factors associated with intention to use contraceptive methods were age, education, the information was given by health facility, age at first cohabitation, the ideal number of children, Wealth status, and Regions that were significant.

Conclusion: We observed various distributions among regions. Education status and various sociocultural aspects need serious considerations to increase the intention to use contraceptive methods. Besides the efforts done, policy decisions might need to consider this finding and uphill the intervention against associated factors like socio-cultural and demographic variables in those areas.

\section{Background}

Irrespective of the type of modern contraceptive women intended to use, World Health Organization (WHO) put no restriction on contraceptive methods unless unacceptable health risks outweigh the worth of utilizing (1).

Using modern contraceptive methods has got enormous influences on the health of mothers and children. Using contraceptive methods has been seen to control family size and unnecessary pregnancies. These lead to a safe life for the mother and child and a safer economy for the family size. A woman may incline toward contraceptive methods use even though many factors might make things difficult for her. The intention to use contraceptive methods is associated with some socio-demographic variables in Africa (2). The socio-demographic factor of the women like age, place of residence, marital status, education, religion, work, frequency of visit to health institution, and awareness of the ovulation cycle has affected intention to use contraception methods(3). According to the Studies in East Africa, 
contraception use was also correlated to parity and attitude (4). Those socio-demographic factors were common in most African countries to affect contraceptive use intention. It became explicit when marital status, Wealth category, Education level, place of residence, number of children, age, religion, and access to a health facility reported in East, South, and West African countries are influencing factors (4-8)

In Ethiopia, data from EDHS (Ethiopian demographic health survey) 2011 and 2016 indicated clear implications on under-five mortality magnitude (9). There was a variation among regions and city administrations regarding contraceptive use. A piece of information from EDHS 2016 showed that the variation observed was region-based (10). However, studies showed a continuous assessment of contraceptive use and their drawbacks, risks, and increasing societal commitment regarding the expansion of them to reduce the risk of unwanted pregnancy is necessary(11). Educating Women, improving women's awareness, involving males in counseling, and focusing on postpartum contraceptive initiation were advised frequently in developing countries to increase intention (12). Other factors from studies include: sharing information with husband/partner, counseling for contraceptives, education more than primary, the desired number of children correlated to intention to use (13).

Studies found women from educated families use contraceptive methods mostly for emergencies (14). In Ethiopia, postpartum contraceptive use is the strategies to increase contraception use; however, the usage is still small. Reasons like cultural and traditional barriers, low male approval, low antenatal visits, inadequate knowledge, and fertility advice correlated (15). From EDHS 2011, we knew the intention to use was $44.1 \%$. During that time, the number of children alive, age at marriage, media exposure, employment status, education of women and her partner, information obtained from health facilities had positive associations (16). Even though contraceptive usage increased 15 folds in some of the regions in Ethiopia in the last 20years, the level remains below par, and attitude, religion, and less husband involvement took responsibilities for decrements (17-21). There is a policy under implementation that state increasing the use of contraceptive from $42 \%$ in 2014 to $55 \%$ in 2020 (22). And the status of the achievement of this policy with spatially informing studies is very crucial. Some studies applied multilevel analysis to identify related implementations when considering different clusters $(10,23,24)$. Despite this, most studies in the country were dealing with contraceptive prevalence, side effects, and socio-demographic factors; regarding the distribution of intention at the country level through spatial mapping as there was little information in this area. In Ethiopia, intention to use contraceptive methods remained limited to picture out the direction for planning and policy decisions. Large-scale studies which picture the contraception intention status might give a piece of representative knowledge for planning and policy decisions. Thus, the current study used country-represented data from EDHS 2016 to discover the unmet to use contraceptives.

\section{Methods And Materials}

We employed a cross-sectional study design using data from Ethiopia Demographic Health Survey (EDHS) 2016. Ethiopia is the country located in Eastern Africa $\left(30-140 \mathrm{~N}, 330-48^{\circ} \mathrm{E}\right)$ and is the $2 \mathrm{nd}$ most populous country in Africa. EDHS is the country representative sample survey within five years intervals 
starting from 2000 in the country. Ethiopia has nine regions (Afar, Amhara, Benishangul-Gumuz, Gambela, Harari, Oromia, Somali, Southern Nations, Nationalities, and People Region (SNNPR), and Tigray), and two town administrations (Addis Ababa and Dire-Dawa). We retrieved the data for this study from the EDHS website www.dhsprogram.com after the request to access approved and downloading allowed. Then 5,651 reproductive age (15-49years) women who never used contraceptive methods pooled from the dataset of EDHS 2016.

The dependent variable for this study is the intention to use contraceptive methods. We measured the variable as use later $(1=y e s)$ and unsure about use or not intend $(0=$ no). The independent variable included: region, type of place of residence, pregnancy termination, heard family planning on the radio in the last few months, read family planning in newspapers/magazines in the past few months, heard family planning on television in the past few months, ever terminated pregnancy, visited field worker in the last 12 months, went to a health facility in the past 12 months, told family planning at a health facility, working status, age, highest education achieved, wealth index, religion, total children ever born, the ideal number of children, husband education, and age at first cohabitation.

Data management consisted of descriptive statistics where STATA 15, ArcGIS 10.7, and SaTscan 9.6.1 soft wares were applied accordingly. Since the data showed a hierarchical nature and inter-cluster variation, we assumed multilevel logistic regression to account for the variations. Then the Likelihood Ratio (LR) test, Intra-class Correlation Coefficient (ICC), Median Odds Ratio (MOR), and Proportional Change in Variance (PCV) examined.

We calculated the dis-similarities of the intention to use contraceptive methods among clusters using ICC

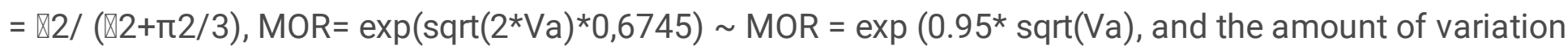
of intention to use contraceptive methods at individual and community level is PVC, where var(null model $)=$ initial variance of the model, $\operatorname{var}($ final model $)=$ variance of the final model, $V a$ in MOR indicates areal level variance, Where; $\operatorname{var}($ null model $)=$ variance of the initial model, and var (final model $)=$ variance of the final model $(25,26,27)$.

We employed binary logistic regression during the analysis for both individual and community-level variables. We built four models. The first model was an intercept-only model showing only the variation among clusters; the second model included individual-level variables; the third model included community-level variables; the fourth included all individual and community-level variables. Each variable was filtered at a $p$-value $<0.25$ before both level analyses. We maintained the statistical significance at a p-value $<0.05$ with an adjusted odds ratio and $95 \%$ confidence interval. Comparison of models applied deviance (-2LL); the lower deviance indicated more model fitness.

We cross-tabulated the weighted frequency of dependent variables and cluster number to obtain the case to total proportion ratio. We dropped Latitudes/longitude with zero coordinates and then applied spatial analyses using ArcGIS 10.7. We applied Global Moran's I to evaluate and check if we have clustered, dispersed, or randomly distributed data across the study area. Significant positive and negative Moran's I index value indicated an inclination to clustering and dispersion in sequence. Getis-OrdGi* statistics 
computed and Showed hot/cold spot area using Z-score and acceptable p-value. The Ordinary Kriging interpolation technique was employed to predict un-sampled areas. We used the Bernoulli model to test the statistical significance of clusters by the Kulldorff's Sat Scan version 9.6.1.)(28).

We accessed data for this study from the Demographic Health Survey (DHS) website (http://www.dhsprogram.com). The access only requests registration for permission. We used the data only for the research purpose. We kept it confidential; we avoided any effort of identifying households or individuals. The EDHS data collection obtained permission from Ethiopian Health Nutrition and Research Institute (EHNRI) Review Board and the National Research Ethics Review Committee (NRERC) at the Ministry of Science and Technology, approved EDHS credentialed. During data collection, they collected verbal informed consent from participants and explained the purpose as it was published in the 2016 EDHS report (29). Participation in the survey was voluntary.

\section{Results}

From the total of 5,651 reproductive age (15-49years) women population extracted from the EDHS 2016 dataset, $44.11 \%$ had an intention to use contraceptive methods. The mean number of children ever born to women in the survey was $4.5 \pm 2.9$, while the average age at first cohabitation was $16.9 \pm 3.99$, and the mean ideal number of children reported $4.77 \pm 2.0$. We used a weighted frequency for the included women at the community level, and the larger numbers were from Oromo (43.78\%), Amhara (19.51\%), and $19.09 \%$ SNNP regions. Greater than three-fourth (88.22\%) of women were from rural-based residences. At the individual level, $2 / 3 \mathrm{rd}(68 \%)$ of women were illiterate (no education), and 1/4th learned at least primary school. Due to this, $18.34 \%, 11.09 \%, \& 2.36 \%$ of them only heard family planning information on radio, $T V$, and newspaper/magazines in sequence. Their exposure to service providers was $26.14 \%$, and $43.66 \%$ were only visited health facilities or met with community health workers respectively in the last 12 months. Indeed only $12.32 \%$ of them have ever terminated a pregnancy. We also described women in terms of other socio-demographic variables and found Muslims and Orthodox Christians as larger religions, $27.68 \%$ currently working women, $45.61 \% \& 34.48 \%$ poor and rich women respectively; $51.61 \%$ of women live with illiterate husbands and age group with higher women were 25-29, 30-34, \& 35-39 and $19.98 \%, 19.49 \%$, \& $17 \%$ respectively; (Table 1 ).

\section{Spatial Results}

We analyzed the spatial data based on the coordinates captured during the data collection. There we found significant clustering that went well with the statistical analyses we applied. We presented the results in table 2 and fig. 1-4. We applied hotspot and cold spot analysis to show areas with higher and lower future use (fig.1), Ordinary Kriging interpolation applied if these areas are more closely (fig.2), and spatial autocorrelation if the closeness is significant (fig.3). And SaTscan statistics for the number of clusters (fig.4) applied to each of them held significantly. Depending on table 2, there were five most likely clusters observed, among which three (cluster 1-3) showed significant association with intention to use 
contraceptive methods. Cluster one included Gambella, Benishangul, Addis Ababa, and some parts of SNNP and Amhara at (10.298371 N, $34.649187 \mathrm{E})$ coordinates with $588.81 \mathrm{~km}$ radius, cluster two contained the whole Tigray, and almost full Amhara regions at (12.669915 N, $36.775082 \mathrm{E})$ with the radius of $335.28 \mathrm{~km}$, and cluster three contained the whole SNNPR, some part of Oromia, Gambella, Addis, and Benishangule at $(6.934084 \mathrm{~N}, 36.520510 \mathrm{E})$ with the radius of $308.29 \mathrm{~km}$. and relative risk of clusters(1-3)1.88, 1.83, \& 1.50 respectively; (table 2 and fig.4).

\section{Individual and Group Level Analyses}

Since we used the data collected on various clusters, we decided to check for the clustering effect among sampling units. It showed dissimilarities, and a larger ICC confirmed variation among clusters. We handled these variations via multilevel logistic regression analyses. We built four models to account for the inter-cluster differences(Table $3 \& 4$ ). The initial (null) model was the model without predictors (intercept only model) followed by the I-III model for individual and community level predictors. At individual level, compared to age group 15-19, women in age group of 25-29,30-34,35-39,40-44, 45-49 had $58 \%, 72 \%, 90 \%, 97 \%, \& 99 \%$ reduced intention to use contraceptive methods with AOR of $0.42(0.3-0.7)$, $0.28(0.17-0.5), 0.1(0.05-0.18), 0.03(0.02-0.06), \&(0.010(0.004-0.02)$ respectively. Reproductive age women with primary education had a 1.4 likelihood contraceptive use intention with an AOR of 1.4(1.041.8) relative to none educated women. As the number of ever born children increased, the women showed intention for contraceptive use, which increased with an AOR of 1.1(1-1.2); otherwise, women with a larger ideal number of children had $11 \%$ reduced intention to use contraceptive methods with an AOR of $0.89(0.84-0.94)$. The women who obtained information to use contraceptives at health facilities showed 1.6 times more intention with an AOR of 1.6(1.3-21). As age at first cohabitation increased, intention to use contraceptive methods raised 1.04 times with an AOR of 1.04(1-1.06).

At the community level, compared to the women in Tigray, women in Afar, Oromia, Somali, Benishangul, SNNPR, Harari, Addis Ababa, and Dire Dawa had 89\%, 61\%, 96\%, 58\%, 64\%, 85\%, 66\%, \& 80\% reduced intention to use modern contraceptive methods with AOR of $0.11(0.06-0.2), 0.39(0.23-0.64), 0.04(0.02-$ $0.09), 0.42(0.25-0.72), 0.36(0.2-0.67), 0.15(0.08-0.28), 0.34(0.2-0.62), \& 0.2(0.11-0.36)$ respectively; (Table $3)$.

Initially, the null model had $28 \%$ intention of contraceptive use appeared only due to the variation among clusters and the remaining left for individual. We sequentially developed models to handle such variations, the inter-cluster variation reduced by $1 / 4$ th to be only (7\%). The PCV for intention to use contraceptive methods in the initial model escalated to 2.9 times more variable due to the clustering effect. We described the full modeling procedures to handle variation in table 4 below. The variance, ICC, media odds ratio, and deviance decreased, while log-likelihood ratio and proportional change in variances increased and showed good fitness.

\section{Discussion}


In this study, we analyzed the EDHS 2016 data to identify the intention of contraceptive methods among reproductive-age women (15-49years). We extracted a total of 5,651 women from the dataset, among which the intention to use contraceptive methods was $44.11 \%$. Compared to the other findings, the intention to use contraceptive was 31.7\% in Gahanna (8), 44.7\% in Mozambique(30) 42\% in Pakistan(31), 18.2\% in Wellega Ethiopia(31), 38\% in Wolaita Ethiopia(32), and 84.3\% in Aksum Town Ethiopia(32). The discrepancies might be due to the comprehensive nature of our study and higher and may be due to the area; (Table 1)

The average age at first cohabitation in the data was $16.9 \pm 3.99$. In a study in Wolaita, it was 17.6(33) and also reported in other studies $<16 y e a r s$ (34) and $\leq 19$ years (32). These might indicate the average lies between $16 \& 19$ years. The average number of children per participant was $4.5 \pm 2.9$. It was $4.9 \pm 1.9$ in Wolaita zone Ethiopia (32), in North West Ethiopia $>3(35)$. In another study, $38 \%$ of women reported $>5$ children per household (9). The mean looked similar throughout the country, and there was only a little difference among them. It might show the average number of children per household is between these numbers. Increasing family planning-related resources and making the intended women access the service might reduce that. However, the mean ideal number of children reported by the women was $4.77 \pm 2.0$, which coincided with the total ever borne number of children. It was also inconsistent compared to the finding in Aksum town (2 \pm 1.5$)(35)$. In another investigation, $35.5 \%$ of women had five-plus ideal plans for the number of children (32). With all efforts to increase family planning in the last 15 years in Ethiopia, many inconsistent reports indicating the average more remained ahead.

More than 2/3rd of the women were illiterates. The number was not shy relative to another study in the country where it was $63 \%(9)$. In Wolaita Sodo town, $32 \%$ of women in this group were without formal education (16). In the Tigray region, $43.2 \%$ of women not educated (18), and $62.1 \%$ not educated in another study (33). The discrepancies of the finding indicate education might be the main reason behind the intention.

It was even expressive when only $2.4 \%$ of participants used newspapers/magazines for obtaining information. Learning less education deprives women of information access in developing countries. Uneducated women might not be aware as educated ones use services available for reproductive health. Only $43.66 \%$ of the women had health facilities visit in the last 12 months. Only $27.68 \%$ of the women had formal work. Studies indicated that non-working women don't attend school and had less intention to use contraceptive methods (33), (13). Adequate Socioeconomic status was usually associated with health services utilization and birth planning, while the opposite is also true. In underdeveloped countries, women have no work, are poorly educated (both couples), and economically poor. These concerns need to be managed as the major issues to solve utilization problems $(5,36-38)$; (Table1).

The significance clustering we have observed was another approach that explained the percentage distribution of intention to use contraceptive methods in the country, and this wasn't happened by chance. The intent to use contraceptives methods has clustered in Northwest Ethiopia(10); (Table 2) 
And this sparked some questions about whether the distribution followed some socio-demographic paths (fig. 1, 2, 3, \& 4). Evidence indicated the Northern part of the country mostly Orthodox believers, Eastern part Muslims, and southern and western parts protestants (39-40); (table 2).

The intention to use contraceptives was higher in the age group of 15-19 than all other age groups. This finding has support from another study in Ethiopia (32). The possible explanation might be more intention of contraceptive use exists at an early age or before marriage. The current educational motivation due to different international efforts like the Millennium development goal might influence these things. Participants in the study in Gahanna showed the reverse intention compared to our study; the participants with primary education as their highest education had no intent to use contraceptive methods in that study (2). That might indicate an intention to learn and use contraception was correlated. In other words, the finding is consistent with the result in North West Ethiopia. It means primary education influence might be different in different African countries. Women with a higher number of children showed more tendencies to use contraceptive methods, which is more global among many studies ( 9 , 34). Women who obtained information on contraceptive methods in health facilities became the other groups to show intention. It indicates that healthcare availability or accessibility increased counseling by health professionals and affected the intent (41); (Table 3)

Women with increased age at first cohabitation had better intention to use contraceptive methods compared to the earlier. However, in Uganda, age at sexual debut has influenced future contraceptive use than the age at first cohabitation $(42,43)$. The inconsistent information might be due to the difference in legality concept of sexual intercourse and cut year concerning marriage where most women might report that after marriage for a cultural reason differ. Compared to the Tigray region, less intention was observed almost in all others especially, in the South and Eastern parts. It might indicate, the Tigray region has better contraceptive methods awareness and has good experience to learn from $(31,35,44)$; (Table 1). Despite these, the current study has many limitations. Limitations of the sampling distribution and clustering effect from the difference in regions were well handled during analysis using pooled frequencies and multilevel analyses; (Table 4). Although we managed these, other limitations like removing data without coordinates and using third-party data might be some other limitations that need consideration while applying our findings.

\section{Conclusion}

The intent to use contraceptive methods was distributed differently in different regions. Socioeconomic and demographic factors might be the reasons. Education and socio-cultural aspects need serious considerations to increase engagement in the services that include family planning. Tigray had good intentions and contraceptive uses; thus, using the region as the focal for experience sharing for others. Education showed a virtuous correlation with the intent to use contraception. So, Educating women might increase the intention and use of contraceptive methods. Promoting women to start cohabitation at a later age could improve their intent to use contraceptive methods. From the result, we learned high intention among women who have started cohabitation at a later-age. Additionally, employing and 
empowering the women might improve the intention and contraception utilization since only less than $1 / 3$ rd of the women were currently working during the survey.

\section{Abbreviations}

WHO = World Health Organization

EDHS = Ethiopian Demographic Health survey

AOR = Adjusted Odds Ratio

$\mathrm{Cl}=$ confidence interval

SNNPR /SNNP = South Nations Nationalities people Region

EHNRI = Ethiopian Health Nutrition and Research Institute

NRERC $=$ Review Board and the National Research Ethics Review Committee

\section{Declarations}

\section{Ethics approval and consent to participate}

We accessed data for this study from the Demographic Health Survey (DHS) website (http://www.dhsprogram.com). We kept it confidential; we avoided any effort of identifying households or individuals. The EDHS data collection obtained permission from Ethiopian Health Nutrition and Research Institute (EHNRI) Review Board and the National Research Ethics Review Committee (NRERC) at the Ministry of Science and Technology, approved EDHS credentialed. During data collection, they collected verbal informed consent from participants and explained the purpose as it was published in the 2016 EDHS report (29). Participation in the survey was voluntary.

\section{Consent for publication}

Not applicable

\section{Availability of data and material}

The data used in this study are the third-party data which is Demographic and Health Survey available at (http://www.dhsprogram.com ). To access the data, someone needs to follow the steps indicated web address and the protocol in the methods section.

\section{Competing interests}

The authors declare that they have no competing interests. 


\section{Funding}

We received no funds for this work.

\section{Authors' contributions}

GG developed the proposal, writing results, and drafting the manuscript while SH was involved in the conception, analysis, and reviewing of the document.

\section{Acknowledgements}

The authors are thankful for the EDHS program personals for the permission to use the data, and all other stakeholders involved directly or indirectly including the people who responded to questions presented to them during the survey.

\section{Authors' information}

Both authors are senior lecturers at the Department of health informatics Arba Minch University College of Health Science Nech Sar campus, South West Ethiopia

\section{References}

1. Altshuler AL, Gaffield ME, Kiarie JN. The WHO's medical eligibility criteria for contraceptive use: 20 years of global guidance. Curr Opin Obstet Gynecol. 2015 Dec;27(6):451-9.

2. Ahuja M, Frimpong E, Okoro J, Wani R, Armel S. Risk and protective factors for intention of contraception use among women in Ghana. Health Psychol Open. 2020 Jul 1;7(2):2055102920975975.

3. Mandiwa C, Namondwe B, Makwinja A, Zamawe C. Factors associated with contraceptive use among young women in Malawi: analysis of the 2015-16 Malawi demographic and health survey data. Contracept Reprod Med. 2018 Sep 20;3(1):12.

4. Obwoya JG, Wulifan JK, Kalolo A. Factors Influencing Contraceptives Use among Women in the Juba City of South Sudan [Internet]. Vol. 2018, International Journal of Population Research. Hindawi; 2018 [cited 2021 Jan 3]. p. e6381842. Available from: https://www.hindawi.com/journals/ijpr/2018/6381842/

5. Makau A. Multinomial Logistic Regression for Modeling Contraceptive Use Among Women of Reproductive Age in Kenya. Am J Theor Appl Stat. 2016;5(4):242.

6. Lakew Y, Reda A, Tamene H, Benedict S, Deribe K. Geographical variation and factors influencing modern contraceptive use among married women in Ethiopia: Evidence from a national population based survey. Reprod Health. 2013 Sep 26;10:52.

7. Agyemang J, Newton S, Nkrumah I, Tsoka-Gwegweni JM, Cumber SN. Contraceptive use and associated factors among sexually active female adolescents in Atwima Kwanwoma District, 
Ashanti region-Ghana. Pan Afr Med J [Internet]. 2019 Dec 4 [cited 2021 Jan 3];32(182). Available from: https://www.panafrican-med-journal.com/content/article/32/182/full/

8. Bawah AA, Asuming P, Achana SF, Kanmiki EW, Awoonor-Williams JK, Phillips JF. Contraceptive use intentions and unmet need for family planning among reproductive-aged women in the Upper East Region of Ghana. Reprod Health. 2019 Dec;16(1):1-9.

9. Bitew F, Nyarko SH. Modern contraceptive use and intention to use: implication for under-five mortality in Ethiopia. Heliyon. 2019 Aug 1;5(8):e02295.

10. Tegegne TK, Chojenta C, Forder PM, Getachew T, Smith R, Loxton D. Spatial variations and associated factors of modern contraceptive use in Ethiopia: a spatial and multilevel analysis. BMJ Open. 2020 Oct 12;10(10).

11. Frost JJ, Singh S, Finer LB. Factors Associated with Contraceptive Use and Nonuse, United States, 2004. Perspect Sex Reprod Health. 2007 Jun;39(2):90-9.

12. Ashebir W, Tadesse T. Associated Factors of Postpartum Modern Contraceptive Use in Burie District, Amhara Region, Ethiopia. J Pregnancy. 2020 Mar 21;2020:1-9.

13. Gedefaw G, Wondmieneh A, Demis A. Contraceptive Use and Method Preferences among HIV Positive Women in Ethiopia: A Systematic Review and Meta-analysis [Internet]. Vol. 2020, BioMed Research International. Hindawi; 2020 [cited 2021 Jan 2]. p. e6465242. Available from: https://www.hindawi.com/journals/bmri/2020/6465242/

14. Mishore KM, Woldemariam AD, Huluka SA. Emergency Contraceptives: Knowledge and Practice towards Its Use among Ethiopian Female College Graduating Students [Internet]. Vol. 2019, International Journal of Reproductive Medicine. Hindawi; 2019 [cited 2021 Jan 2]. p. e9397876. Available from: https://www.hindawi.com/journals/ijrmed/2019/9397876/

15. Gebeyehu NA, Lake EA, Gelaw KA, Azeze GA. The Intention on Modern Contraceptive Use and Associated Factors among Postpartum Women in Public Health Institutions of Sodo Town, Southern Ethiopia 2019: An Institutional-Based Cross-Sectional Study. BioMed Res Int. 2020 Oct 8;2020:1-9.

16. Tiruneh FN, Chuang K-Y, Ntenda PAM, Chuang Y-C. Factors associated with contraceptive use and intention to use contraceptives among married women in Ethiopia. Women Health. 2016 Jan 2;56(1):1-22.

17. Medhanyie AA, Desta A, Alemayehu M, Gebrehiwot T, Abraha TA, Abrha A, et al. Factors associated with contraceptive use in Tigray, North Ethiopia. Reprod Health. 2017(14):27.

18. Alemayehu M, Lemma H, Abrha K, Adama Y, Fisseha G, Yebyo H, et al. Family planning use and associated factors among pastoralist community of afar region, eastern Ethiopia. BMC Womens Health. 2016 Jul 18;16(1):39.

19. Ashebir W, Tadesse T. Associated Factors of Postpartum Modern Contraceptive Use in Burie District, Amhara Region, Ethiopia. J Pregnancy. 2020 Mar 21;2020:1-9.

20. Kebede A, Abaya SG, Merdassa E, Bekuma TT. Factors affecting demand for modern contraceptives among currently married reproductive age women in rural Kebeles of Nunu Kumba district, Oromia, Ethiopia. Contracept Reprod Med. 2019 Dec 5;4(1):21. 
21. Mosisa G, Tsegaye R, Wakuma B, Mulisa D, Etefa W, Abadiga M, et al. Fertility desire and associated factors among people living with HIV in Ethiopia: a systematic review and meta-analysis. Arch Public Health. 2020 Nov 23;78(1):123.

22. Ethiopian Central Statistics Agency; Population Reference Bureau; 2014 United Nations Department of Economic and Social Affairs; World Bank

23. Elo I. Intra-class correlation in random-effects models. 2003;(1):32-46.

24. Merlo J, Chaix B, Ohlsson H, Beckman A, Johnell K, Hjerpe P, et al. A brief conceptual tutorial of multilevel analysis in social epidemiology: Using measures of clustering in multilevel logistic regression to investigate contextual phenomena. J Epidemiol Community Health. 2006;60(4):290-7.

25. Merlo J, Chaix B, Ohlsson H, Beckman A, Johnell K, Hjerpe P, et al. A brief conceptual tutorial of multilevel analysis in social epidemiology: Using measures of clustering in multilevel logistic regression to investigate contextual phenomena. J Epidemiol Community Health. 2006;60(4):290-7.

26. Normal Model with Weights: Huang L, Huang L, Tiwari R, Zuo J, Kulldorff M, Feuer E. Weighted normal spatial scan statistic for heterogeneous population data. Journal of the American Statistical Association, 2009, 104:886-898. [online].

27. Central Statistical Agency (CSA) [Ethiopia] and ICF. Ethiopia Demographic and Health Survey 2016. Addis Ababa, Ethiopia, and Rockville, Maryland, USA: CSA and ICF.

28. Ramos Mboane, Madhav P Bhatta. Influence of a husband's healthcare decision making role on a woman's intention to use contraceptives among Mozambican women. Reprod Health. 2015;12:36.

29. Agha: Intentions to use contraceptives in Pakistan: implications for behavior change campaigns. BMC Public Health 2010 10:450.

30. Tekelab T, Sufa A, Wirtu D (2015) Factors Affecting Intention to Use Long Acting and Permanent Contraceptive Methods among Married Women of Reproductive Age Groups in Western Ethiopia: A Community Based Cross Sectional Study. Fam Med Med Sci Res 4: 158. doi:10.4172/23274972.1000158.

31. Meskele and Mekonnen: Factors affecting women's intention to use long acting and permanent contraceptive methods in Wolaita Zone, Southern Ethiopia: A cross-sectional study. BMC Women's Health 2014 14:109.

32. Abraha TH, Belay HS, Welay GM. Intentions on contraception use and its associated factors among postpartum women in Aksum town, Tigray region, northern Ethiopia: a community-based crosssectional study. Reprod Health. 2018 Nov 9;15(1):188.

33. Fentanesh Nibret Tiruneh MSc, Kun-Yang Chuang PhD, Peter A. M. Ntenda MSc \& Ying-Chih Chuang $\mathrm{PhD}$ (2016) Factors associated with contraceptive use and intention to use contraceptives among married women in Ethiopia, Women \& Health, 56:1, 1-22, DOI: 10.1080/03630242.2015.1074640.

34. Fekadu GA, Omigbodun AO, Roberts OA, Yalew AW. Factors associated with long acting and permanent contraceptive methods use in Ethiopia. Contracept Reprod Med. 2019 Aug 1;4(1):9.

35. Semachew Kasa A, Tarekegn M, Embiale N. Knowledge, attitude and practice towards family planning among reproductive age women in a resource limited settings of Northwest Ethiopia. BMC 
Res Notes. 2018 Aug 13;11(1):577.

36. Hailay Syum, Gizienesh Kahsay, Teklehaymanot Hulu, Berhe Beyene, Hadgu Gerensea, Gebreamlak Gidey, et al. Intention to use long-acting and permanent contraceptive methods and associated factors in health institutions of Aksum Town, North Ethiopia. BMC Res Notes. 2019;12:739.

37. Lasong J, Zhang Y, Gebremedhin SA, Opoku S, Abaidoo CS, Mkandawire T, et al. Determinants of modern contraceptive use among married women of reproductive age: a cross-sectional study in rural Zambia. BMJ Open. 2020 Mar 1;10(3):e030980.

38. Tiruneh F, Chuang K-Y, Ntenda P, Chuang Y-C. Factors Associated With Contraceptive Use and Intention to Use Contraceptives Among Married Women in Ethiopia. Women Health. 2015 Jul 25;56.

39. Gebremariam A, Addissie A. Intention to use long acting and permanent contraceptive methods and factors affecting it among married women in Adigrat town, Tigray, Northern Ethiopia. Reprod Health. 2014 Mar 16;11:24.

40. Religious Beliefs In Ethiopia [Internet]. WorldAtlas. [cited 2021 Feb 10]. Available from: https://www.worldatlas.com/articles/religious-beliefs-in-ethiopia.html

41. Ethiopia Religions - Demographics [Internet]. [cited 2021 Feb 10]. Available from: https://www.indexmundi.com/ethiopia/religions.html

42. Ethiopia - Education [Internet]. Encyclopedia Britannica. [cited 2021 Feb 10]. Available from: https://www.britannica.com/place/Ethiopia

43. Fruhauf T, Zimmerman L, Kibira SPS, Makumbi F, Gichangi P, Shiferaw S, et al. Measuring family planning quality and its link with contraceptive use in public facilities in Burkina Faso, Ethiopia, Kenya and Uganda. Health Policy Plan. 2018 Sep;33(7):828-39.

44. Ariho P, Kabagenyi A. Age at first marriage, age at first sex, family size preferences, contraception and change in fertility among women in Uganda: analysis of the 2006-2016 period. BMC Womens Health. 2020 Jan 16;20(1):8.

\section{Tables}

Table 1: the descriptive characteristics of the study participants extracted from EDHS-2016 for reproductive women (15-49years). 


\begin{tabular}{|c|c|c|c|}
\hline Variables & $\begin{array}{l}\text { Weighted } \\
\text { frequency (\%) }\end{array}$ & Variables & $\begin{array}{l}\text { Weighted } \\
\text { frequency (\%) }\end{array}$ \\
\hline \multicolumn{2}{|l|}{ Highest educational level } & \multicolumn{2}{|l|}{ Types of residence } \\
\hline No education & $3,717.96(68.12)$ & Urban & 643.15(11.78) \\
\hline Primary education & $1,370.29(25.10)$ & Rural & $4,815.1(88.22)$ \\
\hline Secondary education & $220.0(4.03)$ & & \\
\hline Higher education & $150.04(2.75)$ & & \\
\hline \multicolumn{2}{|l|}{$\begin{array}{l}\text { Heard FP on the radio in the last } \\
\text { few months }\end{array}$} & \multicolumn{2}{|l|}{ Religion } \\
\hline \multirow{4}{*}{$\begin{array}{l}\text { No } \\
\text { Yes } \\
\text { Heard FP on TV in the last few } \\
\text { months }\end{array}$} & & Orthodox & $1,916.24(35.41)$ \\
\hline & $4,380.84(81.66)$ & protestant & $1,114.6(20.60)$ \\
\hline & 983.67(18.34) & Muslim & $2,297.38(42.45)$ \\
\hline & & Others & $83.26(1.54)$ \\
\hline No & & & \\
\hline Yes & $4,769.61(88.91)$ & \multicolumn{2}{|l|}{ Respondent currently } \\
\hline \multirow{2}{*}{$\begin{array}{l}\text { Read FP o newspaper/ } \\
\text { magazine in the last few months }\end{array}$} & 594.92(11.09) & \multicolumn{2}{|l|}{ 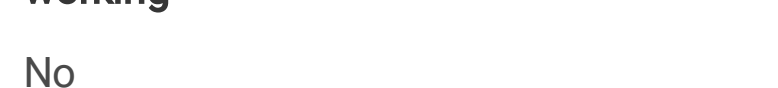 } \\
\hline & & & $3,879.54(72.32)$ \\
\hline \multicolumn{2}{|l|}{ No } & \multicolumn{2}{|l|}{ Wealth status } \\
\hline Yes & $5,237.77(97.64)$ & & \\
\hline \multirow{2}{*}{$\begin{array}{l}\text { Visited by field workers in the last } \\
12 \text { months }\end{array}$} & $126.76(2.36)$ & $\begin{array}{l}\text { Poor } \\
\text { Middle }\end{array}$ & $2,468.02(45.61)$ \\
\hline & & & $1,077.75(19.92)$ \\
\hline No & & \multirow{3}{*}{ Rich } & $1,865.72(34.48)$ \\
\hline \multirow{2}{*}{ Yes } & $3,962.44(73.86)$ & & \\
\hline & $1,402.1(26.14)$ & & \\
\hline The visited Health facility in the & & \multicolumn{2}{|l|}{ Media exposure } \\
\hline 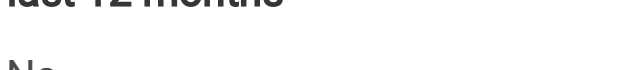 & $3,022.46(56.34)$ & No & $3,556.4(66.29)$ \\
\hline Yes & $2,342.1(43.66)$ & Yes & 1,808.2(33.71) \\
\hline Ever had birth terminated & & Age & \\
\hline No & $4,744.78(87.68)$ & $15-19$ & $312.9(5.73)$ \\
\hline Yes & 666.71(12.32) & $20-24$ & 762.1(13.96) \\
\hline Intention to use contraceptive & & $25-29$ & $1,090.3(19.98)$ \\
\hline
\end{tabular}




\begin{tabular}{|llll|} 
no & & $30-34$ & $1,063.5(19.49)$ \\
Region & $2,998.45(55.89)$ & $35-39$ & $927.76(17)$ \\
Tigray & $2,366.08(44.11)$ & $40-44$ & $665.82(12.2)$ \\
Afar & & $45-49$ & $635.8(11.65)$ \\
Amhara & $365.5(6.70)$ & & \\
Oromia & $72.36(1.33)$ & Husband/partner & \\
Somali & $1,064.77(19.51)$ & education & $2,768.4(51.61)$ \\
Benishangul & $2,389(43.78))$ & No education & $1,905.26(35.52)$ \\
SNNPR & $261.2(4.78)$ & Primary education & $412.7(7.69)$ \\
Gambela & $69.7(1.28)$ & Secondary education & $278.1(5.18)$ \\
Harari & $1,041.8(19.09)$ & Higher education & \\
Addis Ababa & $16.7(0.31)$ & & \\
Dire Dawa & $13.9(0.26)$ & & \\
& $132.3(2.42)$ & & \\
\hline
\end{tabular}

Table 2: most likely clusters of intention to use contraceptive methods among women of childbearing age based on the EDHS 2016

\begin{tabular}{|llllll|}
\hline Clusters & Observed case & Expected cases & RR & LLR & p-value \\
\hline 1 & 1.31 & 959.26 & 1.88 & 141.8 & $<0.001$ \\
\hline 2 & 1.56 & 410.86 & 1.83 & 120.44 & $<0.001$ \\
\hline 3 & 1.35 & 436.4 & 1.5 & 50.7 & $<0.001$ \\
\hline 4 & 1.6 & 31.9 & 1.61 & 8.5 & 0.067 \\
\hline 5 & 1.84 & 8.15 & 1.85 & 4.21 & 0.98 \\
\hline
\end{tabular}

Table 3: Multilevel logistic regression on individual and community-level factors associated with the women (15-49) intention of modern contraceptive methods use. 


\begin{tabular}{|c|c|c|c|c|}
\hline Variables & $\begin{array}{l}\text { Model } \\
0\end{array}$ & Model I & Model II & Model III \\
\hline \multicolumn{5}{|l|}{ Age } \\
\hline $15-19$ & - & 1 & & 1 \\
\hline $20-24$ & - & $0.70(0.45-1.11)$ & & $0.71(0.45-1.13)$ \\
\hline $25-29$ & - & $\begin{array}{l}0.47(0.29- \\
0.76)^{\star \star}\end{array}$ & & $0.42(0.3-0.7)^{\star \star \star}$ \\
\hline $30-34$ & - & $0.34(0.2-56)^{\star \star \star}$ & & $0.28(0.17-0.5)^{\star \star \star}$ \\
\hline $35-39$ & - & $\begin{array}{l}0.11(0.06- \\
0.21)^{\star \star \star}\end{array}$ & & $0.1(0.05-0.18)^{\star \star \star}$ \\
\hline $40-44$ & - & $\begin{array}{l}0.04(0.02- \\
0.08)^{\star \star \star}\end{array}$ & & $\begin{array}{l}0.03(0.02- \\
0.06)^{\star \star \star}\end{array}$ \\
\hline $45-49$ & - & $\begin{array}{l}0.012(0.01- \\
0.03)^{\star \star \star}\end{array}$ & & $\begin{array}{l}0.010(0.004- \\
0.02)^{\star \star \star}\end{array}$ \\
\hline $\begin{array}{l}\text { Highest education level } \\
\text { achieved }\end{array}$ & - & & & \\
\hline No education & - & 1 & & 1 \\
\hline Primary education & - & $1.4(1.1-1.8)^{\star \star}$ & & $1.4(1.04-1.8)^{\star}$ \\
\hline Secondary education & - & $1.2(0.8-2)$ & & $0.1 .3(0.8-2.1)$ \\
\hline Higher education & - & $1.3(0.74-2.4)$ & & $1.4(0.76-2.5)$ \\
\hline $\begin{array}{l}\text { Total number of children ever } \\
\text { born }\end{array}$ & - & $1.2(1.1-1.22)^{\star \star \star}$ & & $1.1(1-1.2)^{\star \star \star}$ \\
\hline $\begin{array}{l}\text { Told FP at a health } \\
\text { facility(HF) }\end{array}$ & - & & & \\
\hline No & - & 1 & & 1 \\
\hline Yes & - & $1.7(1.3-2.1)^{\star \star \star}$ & & $1.6(1.3-21)^{\star \star \star}$ \\
\hline Age at first cohabitation & - & $1.02(0.99-1.05)$ & & $1.04(1-1.06)^{\star}$ \\
\hline Ideal number of children & - & $\begin{array}{l}0.9(0.85- \\
0.95)^{\star \star \star}\end{array}$ & & $\begin{array}{l}0.89(0.84- \\
0.94)^{\star \star \star}\end{array}$ \\
\hline Husband education & - & & Intention & \\
\hline No education & - & 1 & & 1 \\
\hline Primary education & - & $1.4(1.1-1.75)^{\star}$ & & 1.36(1.1-1.7) \\
\hline Secondary education & - & $1.1(0.78-1.6)$ & & $1.2(0.82-1.73)$ \\
\hline
\end{tabular}




\begin{tabular}{|c|c|c|c|c|}
\hline Higher education & - & $0.9(0.57-1.4)$ & & $0.96(0.6-1.5)$ \\
\hline Religion & - & & & \\
\hline Orthodox & - & 1 & & 1 \\
\hline Protestant & - & $\begin{array}{l}0.62(0.44- \\
0.88)^{\star \star}\end{array}$ & & $0.69(0.48-0.98)$ \\
\hline Muslims & - & $\begin{array}{l}0.27(0.2- \\
0.35)^{\star \star \star \star}\end{array}$ & & $0.29(0.22-0.38)$ \\
\hline Others & - & $0.6(0.2-1.78)$ & & $0.67(0.23-1.98)$ \\
\hline Wealth status & - & & & \\
\hline Poor & - & 1 & & 1 \\
\hline Middle & - & $1.4(1.02-1.9)^{*}$ & & $1.4(1.04-1.9)$ \\
\hline Rich & - & $1.4(1.1-1.92) *$ & & $1.6(1.2-2.1)$ \\
\hline Region & - & & & \\
\hline Tigray & - & & 1 & 1 \\
\hline Afar & - & & $\begin{array}{l}0.1(0.07- \\
0.15)^{\star \star \star}\end{array}$ & $0.11(0.06-0.2)^{\star \star \star}$ \\
\hline Amhara & - & & $0.77(0.55-1.1)$ & $1.05(0.66-1.6)$ \\
\hline Oromia & - & & $\begin{array}{l}0.51(0.37- \\
0.69)^{\star \star \star}\end{array}$ & $\begin{array}{l}0.39(0.23- \\
0.64)^{\star \star \star}\end{array}$ \\
\hline Somali & - & & $\begin{array}{l}0.03(0.02- \\
0.05)^{\star \star \star *}\end{array}$ & $\begin{array}{l}0.04(0.02- \\
0.09)^{\star \star \star \star}\end{array}$ \\
\hline Benishangul & - & & $\begin{array}{l}0.52(0.36- \\
0.73)^{\star \star \star}\end{array}$ & $0.42(0.25-0.72)^{\star \star}$ \\
\hline SNNPR & - & & $0.72(0.51-0.99)^{\star}$ & $0.79(0.46-1.36)$ \\
\hline Gambela & - & & $\begin{array}{l}0.34(0.24- \\
0.0 .5) \star \star \star\end{array}$ & $0.36(0.2-0.67)^{\star \star \star}$ \\
\hline Harari & - & & $.2(0.13-0.29)^{\star \star \star}$ & $\begin{array}{l}0.15(0.08- \\
0.28)^{\star \star \star}\end{array}$ \\
\hline Addis Ababa & - & & 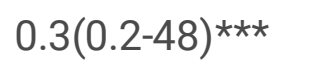 & $0.34(0.2-0.62)^{\star \star \star}$ \\
\hline Dire Dawa & - & & $\begin{array}{l}0.2(0.13- \\
0.31)^{\star \star \star}\end{array}$ & $0.2(0.11-0.36)^{\star \star \star}$ \\
\hline Residence & - & & & \\
\hline Urban & - & & 1 & \\
\hline Rural & - & & $\begin{array}{l}0.69(0.54- \\
0.86)^{\star *}\end{array}$ & $0.87(0.52-1.3)$ \\
\hline
\end{tabular}


NB: ${ }^{*}=p<0.05, * *=p<0.01, \& * \star *=p<0.001 ; F P=$ family planning, south nation nationality people

Table 4: Multilevel logistic regression model comparison and random effect distribution as examined for intention to use contraceptive methods among reproductive age group from EDHS 2016

\begin{tabular}{|lllll|}
\hline Random effect model comparison & Model $\mathbf{0}$ & Model 1 & Model 2 & Model 3 \\
\hline Variance & 1.29 & 0.51 & 0.33 & 0.27 \\
\hline Inter-cluster correlation(ICC) & 0.28 & 0.12 & 0.09 & 0.076 \\
\hline Log likelihood ratio(LLR) & -1372 & -1405 & -3166 & -1301 \\
\hline Deviance & 2744 & 2810 & 6332 & 2602 \\
\hline Proportional change in variance(PCV) & Ref & 0.6 & 0.74 & 0.79 \\
\hline Media odds ratio (MOR) & 2.9 & 1.9 & 1.7 & 1.6 \\
\hline
\end{tabular}

Figures 


\section{Hotspot and cold spot analysis of intention to use contraception}
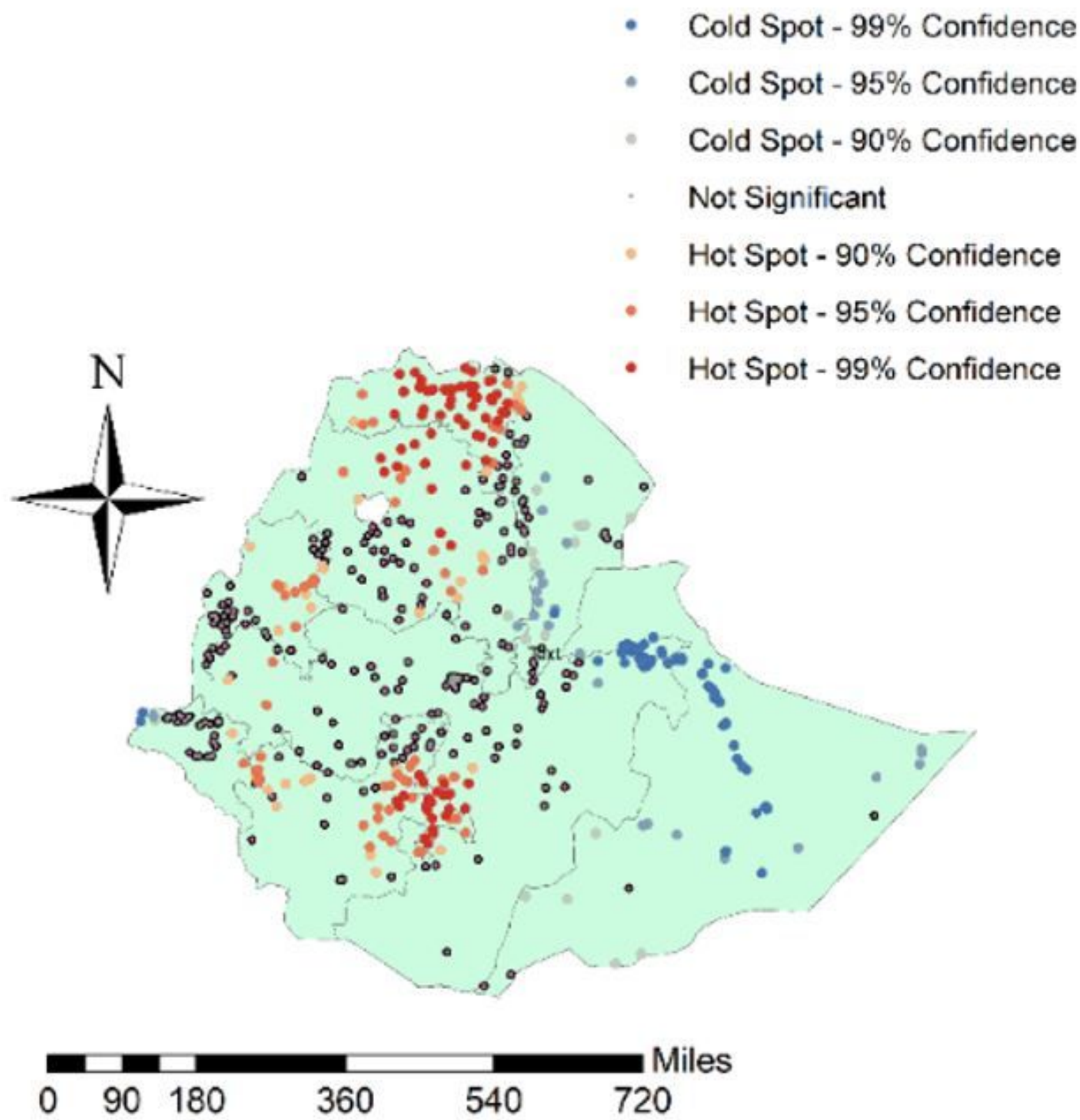

Soure: shase file from Ethiopan central statistics agency iCSA) 2013

\section{Figure 1}

Hot spot and cold spot of intention to use contraceptive in Ethiopian, EDHS 2016 Note: The designations employed and the presentation of the material on this map do not imply the expression of any opinion whatsoever on the part of Research Square concerning the legal status of any country, territory, city or area or of its authorities, or concerning the delimitation of its frontiers or boundaries. This map has been provided by the authors. 


\section{Spatial interpolation of intention to use contraception in Ethio}
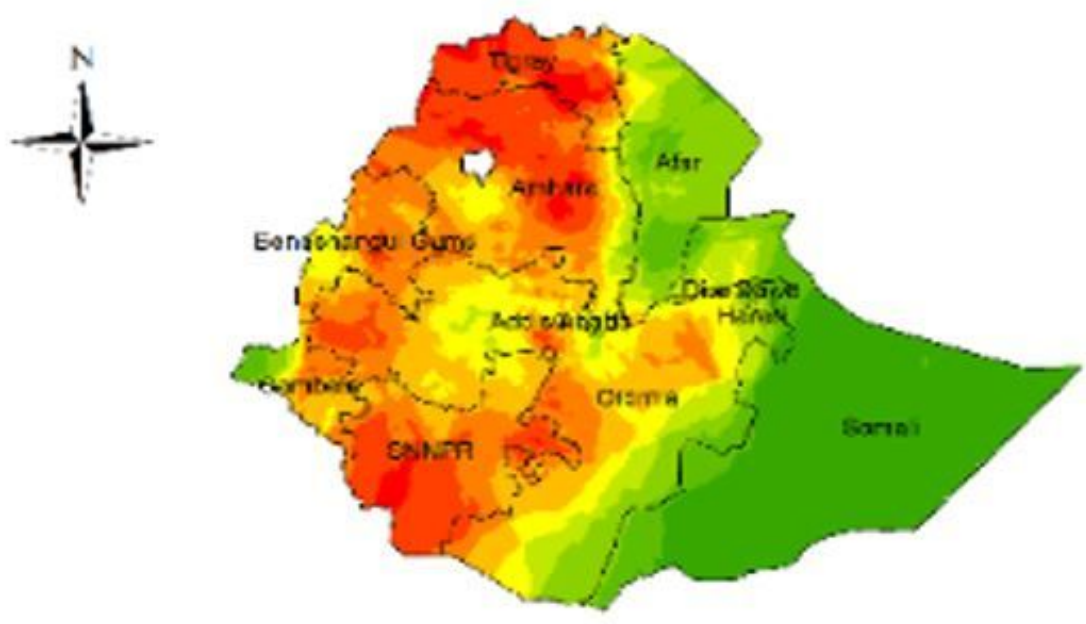

Interpolation
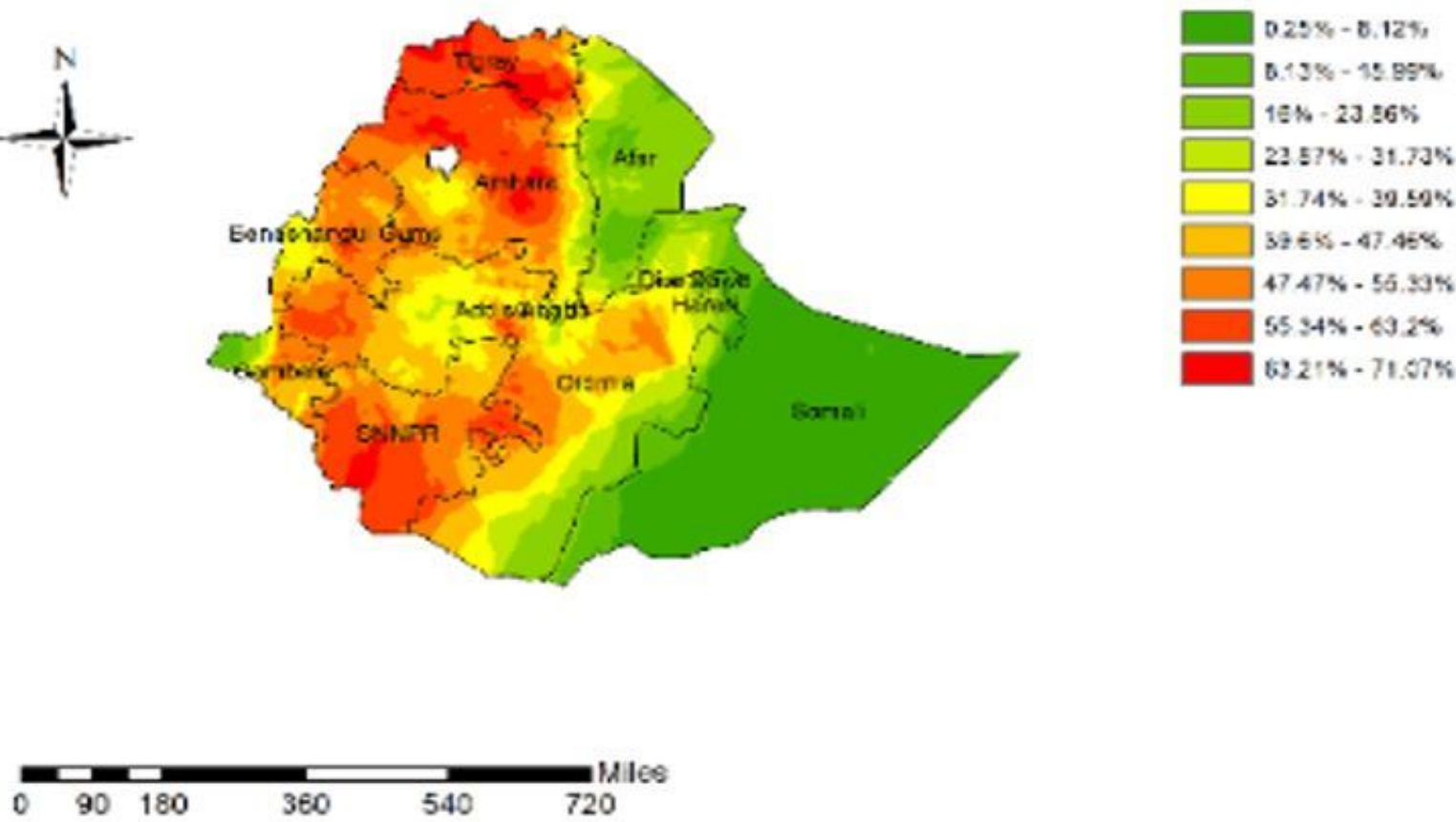

Source: shape file trom Ethiopian central statis5cs agency (CSA), 2013

Figure 2

Ordinary Kriging interpolation of intention to use contraceptive in Ethiopia, EDHS 2016 Note: The designations employed and the presentation of the material on this map do not imply the expression of any opinion whatsoever on the part of Research Square concerning the legal status of any country, territory, city or area or of its authorities, or concerning the delimitation of its frontiers or boundaries. This map has been provided by the authors. 


\section{Spatial Autocorrelation Report}

Moran's Index: 0.088427

z-score: $2.948354 \square$

p-value: 0.003195

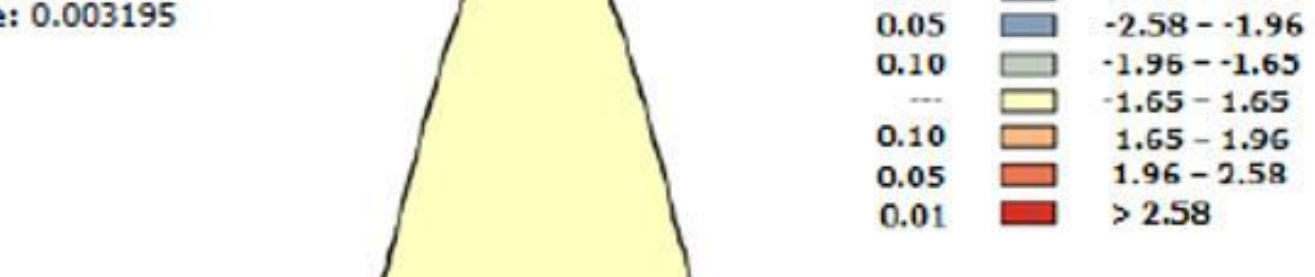

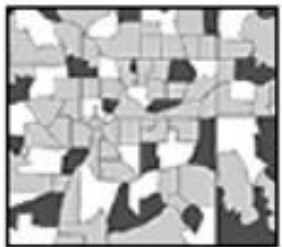

Dispersed

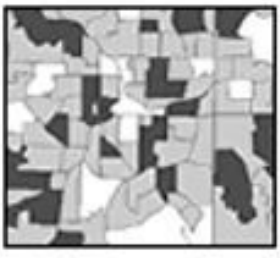

Random
Critical Value (z-score)

$<-2.58$

$-2.58--1.96$

$-1.96--1.65$

$1.65-1.65$

2.58

Given the $z$-score of 2.94835424944 , there is a less than $1 \%$ likelihood that this clustered pattern could be the result of random chance.

\section{Figure 3}

spatial autocorrelation intention to use contraceptive in Ethiopia, EDHS 2016 


\section{Cluster analysis of contraceptive use intention in Ethiopia, 2016}

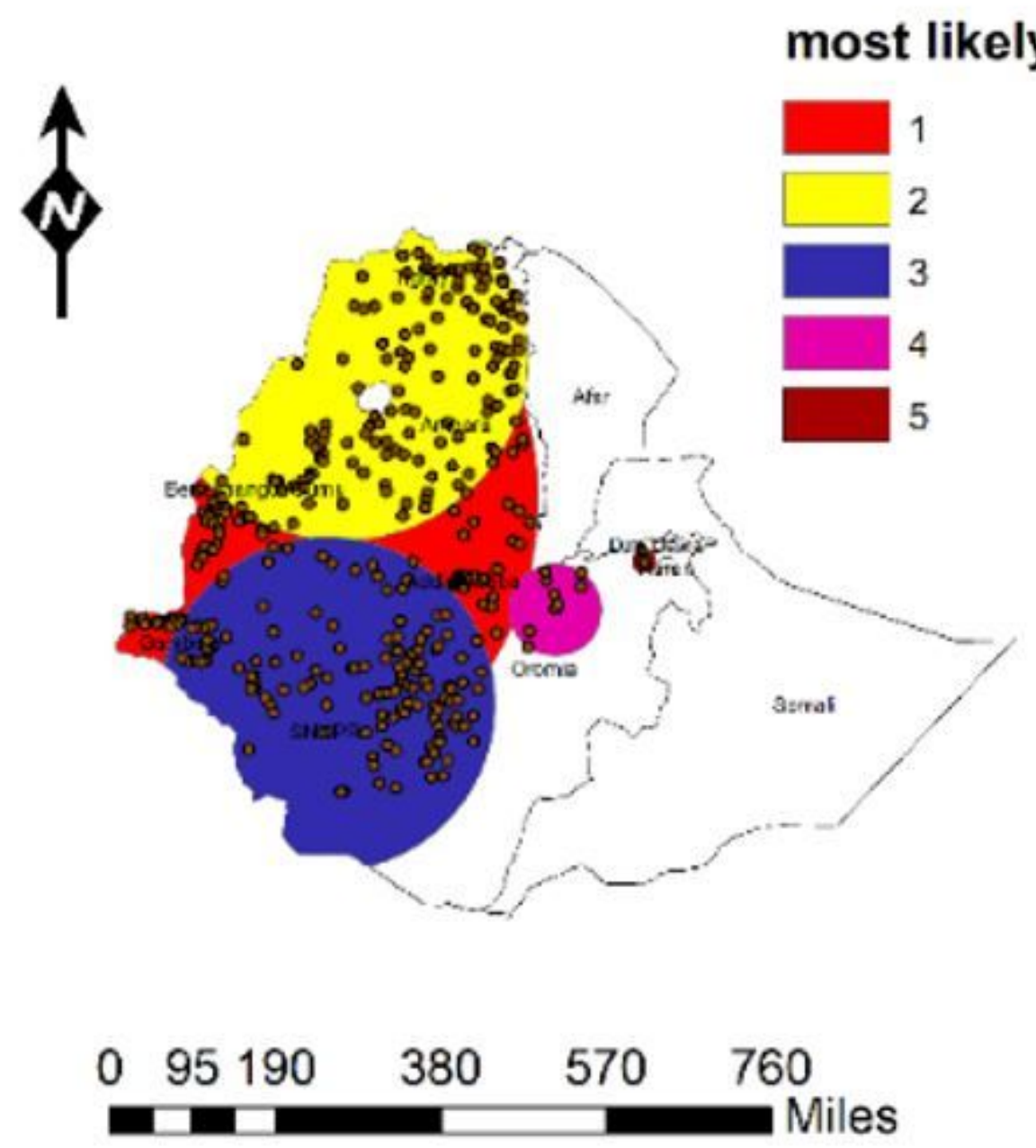

Source: shape file from CSA, Ethopta. 2013

Figure 4

SaTScan scan statistics of intention to use contraceptive in Ethiopia, EDHS 2016 Note: The designations employed and the presentation of the material on this map do not imply the expression of any opinion whatsoever on the part of Research Square concerning the legal status of any country, territory, city or area or of its authorities, or concerning the delimitation of its frontiers or boundaries. This map has been provided by the authors. 